\section{Perfil demográfico dos índios Boróro de Mato Grosso, Brasil, 1993-1996}

\author{
Demographic profile of Boróro Indians from Mato \\ Grosso State, Brazil, 1993-1996
}

\footnotetext{
1 Distrito Sanitário Especial Indigena Xavante, Fundação Nacional de Saúde, Barra do Garças, Brasil.

2 Escola Nacional de Saúde Pública Sergio Arouca, Fundação Oswaldo Cruz, Rio de Janeiro, Brasil.

${ }^{3}$ Departamento de Medicina

Preventiva, Universidade

Federal de São Paulo-Escola

Paulista de Medicina,

São Paulo, Brasil.

4 Museu Nacional,

Universidade Federal do

Rio de Janeiro, Rio de Janeiro,

Brasil.

Correspondência

L. G. Souza

Departamento de Endemias

Samuel Pessoa, Escola

Nacional de Saúde Pública

Sergio Arouca, Fundação

Oswaldo Cruz.

Rua Leopoldo Bulhões 1480,

Rio de Janeiro, $R J$

21041-210, Brasil.

lucienegsouza@uol.com.br
}

\section{Abstract}

This paper analyzes the demographic profile of the Boróro Indians from Mato Grosso State, Brazil, from 1993 to 1996. Data came from annual collection and registration of vital statistics conducted by the health service in three villages (Garças, Meruri, and Morada dos Boróro). The average annual population growth rate was 2.4\%. Nearly half (44\%) of the population was younger than 15 years (median 16 years). The crude birth rate was 30.9 per 1,000 and the crude death rate 7.3 per 1,000 inhabitants. The infant mortality rate was high (58.8 per thousand live births), probably resulting from precarious health conditions in the villages. The results showed that women married younger than men and that there were numerous unmarried adult men (26.7\%) and women (13.3\%), as compared to data from other indigenous groups. The total fertility rate of Boróro women was 4.3, quite low compared to other indigenous communities in Brazil. The study emphasizes the importance of systematically collecting and analyzing demographic data on indigenous populations.

Demography; Fertility; Mortality; South American Indians
Luciene Guimarães de Souza 1,2

Heloisa Pagliaro ${ }^{3}$

Ricardo Ventura Santos 2,4

\section{Introdução}

A sociedade Boróro é, dentre os povos indígenas das terras baixas sul-americanas, uma das mais intensamente estudadas do ponto de vista etnológico. Os estudos têm se centrado, sobretudo, em aspectos da organização social e da cultura $1,2,3,4,5,6,7$, com pouca ênfase em demografia.

As fontes históricas indicam que, nas últimas décadas do século XIX, a população Boróro era de aproximadamente 10 mil indivíduos. Ao cabo de poucos anos, grande parte sucumbiu aos efeitos do contato, que incluíram confrontos, epidemias e fome 8 . O quadro era tão desalentador que o antropólogo Darcy Ribeiro 9, ao analisar um censo indígena em 1932, afirmou que os Boróro rumavam para a extinção física e cultural. Contrariando esta perspectiva catastrófica, a partir da década de 1970 tem-se observado um crescimento populacional dos Boróro. De uma população de 626 indivíduos em 1979, houve um aumento para aproximadamente 1.300 em 2006 (Fundação Nacional de Saúde; http://www.funasa. gov.br, acessado em 02/Nov/2006).

Estudos antropológicos e demográficos sobre povos indígenas específicos no Brasil mostram que algumas sociedades, ainda que tenham experimentado flutuações em seus níveis de mortalidade e de natalidade nas últimas décadas, estão em crescimento positivo 10 . Alguns povos têm crescido em média $3,5 \%$ ao ano 11 , ou quase 
o dobro do conjunto da população brasileira, que cresceu 1,6\% ao ano entre 1991 e 200012.

A maior parte dos povos indígenas no Brasil, sob o ponto de vista demográfico, é formada por micro-sociedades, ou seja, apresentam contingentes populacionais relativamente pequenos, em geral não ultrapassando umas poucas centenas 13,14 . Além do tamanho populacional, muito pouco se sabe sobre a dinâmica demográfica da maioria desses povos. Em geral, é difícil ir além da compilação de estudos de caso, basicamente concentrados na região amazônica 10,15.

Este estudo investiga características demográficas dos Boróro residentes nas aldeias Garças, Meruri e Morada dos Boróro, situadas a leste de Mato Grosso, no período de 1993 a 1996. Buscase contribuir para a ampliação do conhecimento da demografia indígena no Brasil.

\section{População e métodos}

Os Boróro (nome pelo qual ficaram conhecidos e cujo significado é "pátio da aldeia”) se autodenominam "Böe". A sua língua está classificada no tronco lingüístico Macro-Jê. É uma sociedade de metades exogâmicas ("tugarege" e "ecerae"), na qual a regra de descendência é matrilinear, ou seja, a criança recebe um nome que a relaciona ao grupo de parentes de sua mãe.

As aldeias Boróro são tradicionalmente circulares. Mesmo naquelas comunidades onde as casas estão dispostas em arruamentos, por influência de missionários ou agentes do governo, a circularidade da aldeia é considerada a representação ideal do espaço social 6 .

De acordo com Viertler 16 e Wüst 17, os Boróro possuíam no passado aldeias densamente povoadas, por vezes com mais de mil pessoas. Moravam em choupanas de palha, dispostas na forma de anéis concêntricos, no entorno de uma grande choupana central (a casa dos homens), que se constituía no centro político e ritual da aldeia. No presente, as aldeias Boróro possuem, em média, cem habitantes 16. Há uma intensa dinâmica de visitas e de casamentos entre membros das várias comunidades 6 .

Cada casa Boróro costuma abrigar duas ou três famílias nucleares, que têm entre si laços de parentesco. Os grupos residenciais são uxorilocais (ou seja, um homem ao se casar deve se mudar para a casa da esposa). Segundo Novaes 5 , embora haja várias ocasiões em que a uxorilocalidade não é seguida, constitui a norma ideal de residência pós-casamento entre os Boróro.

Atualmente, as 11 aldeias Boróro estão situadas em seis Terras Indígenas localizadas no Estado de Mato Grosso. Essas terras constituem um território descontínuo e, em larga medida, descaracterizado do ponto de vista ecológico (devido a desmatamento, garimpo e fazendas ao redor), correspondendo a uma área cerca de 300 vezes menor que o território tradicional. As Terras Indígenas são as seguintes: Meruri, Perigara, Sangradouro-Volta Grande (ocupada pelos Xavánte e não reconhecida como Boróro) e Tadarimana. A Terra Indígena Jarudori, reconhecida pelo Serviço de Proteção aos Índios (SPI) como Boróro na primeira metade do século XX, foi sendo continuamente invadida e nela hoje se encontra uma cidade. A Terra Indígena Teresa Cristina teve sua delimitação revogada por decreto presidencial alguns anos atrás, estando atualmente sob júdice. Em 1997, os Boróro moradores dessas seis áreas perfaziam 1.024 habitantes (Instituto Socioambiental; http://www.socioambiental.org. br, acessado em 02/Nov/2006).

Em 1976, ocorreu um conflito de disputa por terra que culminou na morte de um missionário salesiano e de um Boróro na Terra Indígena Meruri, o que levou vários indivíduos da aldeia Meruri a se estabelecerem em uma nova aldeia, mais afastada da influência missionária. Nessa nova aldeia (Garças), as casas foram construídas em palha e dispostas em círculo, tal como no modelo tradicional 6 .

O sistema econômico dos Boróro caracteriza-se pela combinação das atividades de coleta, caça, pesca e agricultura. O processo de contato com a sociedade envolvente acarretou novas formas de relações sociais e econômicas, tais como trabalho assalariado, recebimento de proventos de aposentadoria e venda de produtos artesanais. Com a diminuição dos territórios de caça, pesca e coleta, as atividades agrícolas se tornaram centrais na subsistência 4,16 .

Os dados analisados neste trabalho são procedentes do serviço de saúde da Fundação Nacional do Índio (FUNAI). Foram coletados no período de 1993 a 1996 por uma das autoras (L.G.S.), que compunha a equipe de atenção à saúde vinculada à Casa de Saúde do Índio da Administração Regional da FUNAI de Barra do Garças (Mato Grosso), então responsável pela assistência à população das aldeias Garças, Meruri e Morada dos Boróro. Essas comunidades correspondiam a aproximadamente metade da população total da etnia na época do levantamento dos dados. O levantamento incluiu cadastros anuais e registros de eventos vitais. Historicamente, a população Boróro das três aldeias estudadas vem mantendo contato com não-índios desde o início do século XX (1902) através de missionários salesianos, e, mais recentemente, com os Xavánte, desde 19574.

As informações dos cadastros foram coletadas nos domicílios das três aldeias ao longo de 
sete diferentes períodos: de fevereiro a março e em dezembro de 1993; em abril e dezembro de 1994; em julho e dezembro de 1995; e em novembro de 1996. Esses períodos foram aqueles de ida a campo da equipe de saúde com vistas à execução das atividades rotineiras de atenção à saúde. As informações sobre os nascimentos e mortes ocorridos no mês de dezembro de 1996 foram obtidas posteriormente.

Paralelamente aos cadastros, registros dos eventos vitais (mortes e nascimentos) foram checados com aqueles oriundos do ambulatório mantido pela Missão Salesiana e junto ao monitor de saúde da aldeia Garças. Os dados referentes às mortes foram também investigados no Serviço de Saúde da FUNAI (Casa de Saúde do Índio) e nos principais hospitais de referência nos municípios de General Carneiro, Primavera do Leste e Aragarças.

As idades das crianças foram obtidas a partir dos registros da Missão Salesiana, do Posto Indígena da FUNAI e de informações prestadas pelos pais. Cabe lembrar que tanto as comunidades de Meruri quanto Morada dos Boróro vivem no entorno da Missão Salesiana e a população que habita a aldeia Garças é oriunda da aldeia Meruri. Aos adultos perguntou-se a data de nascimento (dia, mês e ano), que foi posteriormente confrontada com os registros da Missão Salesiana e da FUNAI. Muitos adultos possuíam documentação pessoal, embora a existência de tais documentos não garantisse a veracidade dos registros de nascimento, particularmente no caso dos indivíduos que obtiveram suas certidões vários anos após o nascimento.

Foram cadastradas todas as pessoas residentes nas aldeias na data de cada coleta, inclusive as que se encontravam temporariamente ausentes. O conceito de população residente utilizado incluiu os moradores habituais do domicílio, quer estivessem presentes ou ausentes na data de referência. As pessoas ausentes foram incluídas nas contagens desde que as ausências não fossem superiores a 12 meses do cadastro. Na consolidação dos dados sobre os domicílios e a população residente, foi utilizado como data de referência o dia 31 de dezembro de cada ano. De acordo com esse critério, os indivíduos nascidos após a data dos levantamentos (que variou de ano para ano) foram incluídos na pesquisa, sendo também considerados os indivíduos falecidos até aquela data e que residiam no domicílio por ocasião do levantamento.

Para cada indivíduo, foram coletadas as seguintes variáveis: nome, sexo, relação de parentesco no domicílio, nome dos pais, situação de uniões conjugais, número de filhos nascidos vivos, sobreviventes e mortos, data da morte (a partir do segundo levantamento) e pertencimento étnico. Além das características sócio-demográficas, foram levantadas informações sobre a composição e as características das famílias (nucleares e extensas).

Para fins de sistematização das informações, foram preparadas fichas por unidade domiciliar nas quais os registros das famílias residentes e respectivos laços de parentesco foram anotados e atualizados anualmente. Foram registrados também os deslocamentos individuais e familiares, além de construídas genealogias por grupos familiares. Os dados dos domicílios referem-se às famílias residentes e/ou presentes nos grupos domésticos. As famílias foram classificadas como nucleares quando apenas pais e filhos ocupavam um domicílio; e como extensas quando duas, três ou mais famílias nucleares com laços de parentesco ocupavam um mesmo domicílio.

Os dados coletados nas diferentes fontes foram organizados e analisados em planilhas do programa Excel (Microsoft Corp., Estados Unidos), por ano de referência. Para cada indivíduo foi feito um registro codificado, consistindo de: número do registro, comunidade de residência, número do domicílio, além das variáveis individuais indicadas anteriormente. Após a transcrição das fichas, realizou-se a checagem dos dados visando detectar inconsistências e duplicidade de informações.

Foram definidos os seguintes critérios para fins de classificação quanto ao estado conjugal: solteiros - os que não vivessem ou não tivessem vivido em companhia de cônjuge; casados - os que vivessem em companhia do cônjuge; viúvos - aqueles cujos cônjuges tivessem morrido e que não estivessem na companhia de outro cônjuge na ocasião; separados - aqueles anteriormente casados que estivessem separados de seus cônjuges, e não vivessem na ocasião em companhia de outro cônjuge.

Por período reprodutivo das mulheres entende-se aquele que vai desde a idade da menarca até a menopausa. As mulheres de 15 a 49 anos solteiras, separadas ou viúvas foram incluídas nas análises mesmo sem estarem casadas.

Os parâmetros demográficos considerados nas análises foram: tamanho da população; distribuição por sexo, idade, estado conjugal; distribuição por aldeia e domicílio; natalidade; fecundidade; mortalidade; e movimentos migratórios. 


\section{Resultados}

\section{Características das aldeias e das famílias}

As moradias em Meruri e em Morada dos Boróro são de alvenaria e contam com energia elétrica e água encanada. Por influência missionária, essas duas aldeias são constituídas de arruamentos, portanto diferindo da forma circular que é tradicional na sociedade Boróro. Já na aldeia Garças as casas estão dispostas em círculo, havendo no centro a edificação do "Baito Manajejeu" (casa comunitária), tendo a seu lado a área destinada ao "Boróro" (isto é, o local onde são enterrados os mortos).

No período de 1993 a 1996, a população Boróro de Meruri, Garças e Morada dos Boróro cresceu, em média, $2 \%$ ao ano, passando de 393 em 1993 para 418 em 1996. A aldeia Meruri concentrava $71 \%$ (297 habitantes) da população registrada em 1996; Garças e Morada dos Boróro possuíam, respectivamente, 71 e 50 habitantes.

A aldeia Meruri possuía 46 casas em 1996, habitadas em sua maioria por famílias extensas, com uma média de seis indivíduos por domicílio. Garças e Morada dos Boróro possuíam, respectivamente, 11 e 7 casas, habitadas por 7 indivíduos em média.

A maior parte dos 23 imigrantes no período 1993 a 1996 era originária de outros aldeamentos Boróro, em sua maioria da aldeia Tadarimane (17). Dos 27 emigrantes, 15 dirigiram-se à Tadarimane.

Quanto ao sexo dos migrantes, foram 19 homens e 31 mulheres. A maioria dos indivíduos tinha entre 0 e 14 anos de idade, sendo 10 homens e 18 mulheres. Esses migrantes integravam famílias, sendo as migrações individuais geralmente motivadas por casamentos e constituídas majoritariamente de homens entre 15 e 24 anos.

\section{Estrutura populacional por idade e sexo}

Entre 1993 e 1996, as proporções de menores de 15 anos de idade na população total $(46 \%$ e $44,5 \%)$ e de maiores de 65 anos (5,9\% e 6,4\%) se mantiveram praticamente estáveis. A idade mediana para todos os anos considerados foi de 16 anos. Entre 1994 a 1995 houve uma redução populacional (de 424 para 413), o que foi resultante de emigração. Esta diminuição é mais evidente no grupo etário de 5 a 14 anos. Para ambos os sexos, observou-se que a composição proporcional dos diversos grupos etários ao longo dos anos manteve-se relativamente estável (Tabela 1).

A parcela jovem da população representa um peso mais acentuado nos valores da razão de dependência que a parcela de idosos, mostrando que a estrutura de população é relativamente jovem. Isto pode ser também visualizado através do índice de idosos, já que para cada 100 crianças menores de 15 anos existiam 14 adultos maiores de 65 anos em 1995.

Os valores da "razão de sexo", medida definida como o número de homens para cada $100 \mathrm{mu}$ lheres, segundo o grupo etário, são mostrados na Tabela 1. Para todos os anos estudados nota-se o predomínio do sexo masculino em quase todos os grupos etários. Destaca-se o desequilíbrio numérico entre os sexos no grupo de idosos, onde predominam as mulheres.

\section{Natalidade e fecundidade}

A taxa bruta média de natalidade $(\mathrm{TBN})$ para o período analisado foi de 30,9 por mil (Tabela 2). Em 1995 e 1996 observam-se o maior e o menor índice, quais sejam, de 33,9 e 23,9 por mil, respectivamente. Para os outros anos, as variações não foram proeminentes. As taxas de fecundidade geral (TFG) se mantiveram em torno de 12

População Boróro da aldeia Meruri, Garças e Morada dos Boróro, razão de sexos segundo quatro grupos de idade. Mato Grosso, Brasil, $1993-1996$.

\begin{tabular}{|c|c|c|c|c|c|c|c|c|c|c|c|c|c|c|c|}
\hline \multirow{2}{*}{$\begin{array}{l}\text { Grupo } \\
\text { etário } \\
\text { (anos) }\end{array}$} & \multicolumn{3}{|c|}{1993} & \multicolumn{3}{|c|}{1994} & \multicolumn{3}{|c|}{1995} & \multicolumn{3}{|c|}{1996} & \multicolumn{3}{|c|}{ 1993-1996 } \\
\hline & $\mathrm{M}$ & $\mathbf{F}$ & RS & $\mathrm{M}$ & $\mathbf{F}$ & RS & M & $\mathbf{F}$ & RS & M & $\mathbf{F}$ & RS & M & $\mathbf{F}$ & RS \\
\hline $0-4$ & 36 & 34 & 105,9 & 37 & 34 & 108,8 & 35 & 33 & 106,1 & 38 & 32 & 118,8 & 146 & 133 & 109,8 \\
\hline $5-14$ & 65 & 46 & 141,3 & 70 & 55 & 127,3 & 64 & 53 & 120,8 & 62 & 53 & 117,0 & 261 & 207 & 126,1 \\
\hline $15-64$ & 99 & 90 & 110,0 & 102 & 99 & 103,0 & 106 & 97 & 109,3 & 108 & 100 & 108,0 & 415 & 386 & 107,5 \\
\hline $65 e+$ & 8 & 15 & 53,3 & 9 & 18 & 50,0 & 9 & 16 & 56,3 & 10 & 15 & 66,7 & 36 & 64 & 56,3 \\
\hline Total & 208 & 185 & 112,4 & 218 & 206 & 105,8 & 214 & 199 & 107,5 & 218 & 200 & 109,0 & 858 & 790 & 108,6 \\
\hline
\end{tabular}

M: masculino; F: feminino; RS: razão de sexos. 
Taxa bruta de natalidade, taxa de fecundidade global, taxa de fecundidade total, taxa bruta de mortalidade e taxa de mortalidade infantil. Mato Grosso, Brasil, 1993-1996.

\begin{tabular}{|c|c|c|c|c|c|}
\hline Indicadores & 1993 & 1994 & 1995 & 1996 & 1993-1996 \\
\hline Taxa bruta de natalidade (TBN) * & 33,1 & 33,0 & 33,9 & 23,9 & 30,9 \\
\hline Taxa de fecundidade global (TFG) ** & 12,7 & 12,2 & 12,3 & 8,7 & 11,4 \\
\hline Taxa de fecundidade total (TFT) & 4,2 & 4,4 & 4,7 & 3,2 & 4,3 \\
\hline Taxa bruta de mortalidade (TBM) * & 5,1 & 4,7 & 9,7 & 9,6 & 7,3 \\
\hline Taxa de mortalidade infantil (TMI) *** & 0,0 & 71,4 & 71,4 & 100,0 & 58,8 \\
\hline
\end{tabular}

* Por mil habitantes;

** Por mil mulheres em idade reprodutiva;

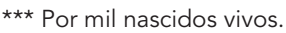

filhos para cada cem mulheres em idade fértil, com exceção do ano de 1996, quando a média foi de 8,7 . No período analisado, oito mulheres tiveram mais de um filho (em todos os casos dois filhos). Para estas mulheres, a média do intervalo intergenésico foi de 25,4 meses (mínimo de 20 meses e máximo de 40 meses).

A taxa de fecundidade total (TFT) para o período de 1993 a 1996 foi de 4,3 filhos por mulher. Uma vez que nem todas as mulheres em idade fértil estavam em uniões estáveis (Tabela 3), calcularam-se em separado as TFT das mulheres que viviam em uniões estáveis e não estáveis. As TFTs encontradas para esses dois grupos de mulheres foram 4,7 e 3,4 , respectivamente.

\section{Nupcialidade}

A população Boróro com 15 ou mais anos de idade apresentava, em 1996, uma proporção de $20,2 \%$ de solteiros, $61,8 \%$ de casados, $5,2 \%$ de viúvos e $12,9 \%$ de separados (Tabela 3). O percentual de mulheres casadas $(63,7 \%)$ era ligeiramente superior que aquele de homens casados (60\%). Observou-se também que na população feminina havia uma maior quantidade de pessoas viúvas $(8,8 \%)$ que na masculina (1,7\%). Chamou atenção a elevada proporção de homens e mulheres separados $(11,7 \%$ e $14,2 \%$, respectivamente).

As mulheres Boróro casam-se mais cedo que os homens. Em 1996, metade das mulheres de 15 a 19 anos já havia se casado (50\%), ao passo que somente $33,3 \%$ dos homens. No grupo etário de 20 a 29 anos, $41,7 \%$ dos homens e $17,9 \%$ das mulheres ainda eram solteiros. Poucas pessoas, independentemente do sexo, se mantinham solteiras ao longo de toda a vida. Na população com 30 anos e mais, havia seis homens e duas mulheres solteiras. No grupo etário de 20 ou mais anos, 13 homens e 14 mulheres estavam separados.

Na população havia seis indivíduos adultos casados e que não eram Boróro, a saber: na aldeia Meruri uma mulher "negra" e um homem da etnia Fulniô, oriundo da Região Nordeste; na Morada dos Boróro, três homens não indígenas ("brancos") e um que se considerava "mestiço", cuja mãe era da etnia Kayabí.

\section{Mortalidade}

Houve uma ampla variação na taxa de mortalidade infantil (TMI) no período, desde 0,0 por mil nascimentos vivos em 1993 a 100 por mil em 1996. O valor médio foi de 58,8 (Tabela 2).

A taxa bruta de mortalidade (TBM) variou entre 4,7 e 9,7 óbitos por mil habitantes no período, com uma média de 7,3 óbitos por mil habitantes. Quanto às taxas específicas de mortalidade por idade, os mais elevados níveis foram registrados entre crianças de 0 a 4 anos (10,8 por mil) e idosos com 65 anos e mais (40,0 por mil) (Tabela 4).

Do total de óbitos registrados, três ocorreram entre menores de um ano, com uma mortalidade proporcional de $25 \%$. A maior parte das mortes (42\%) aconteceu em adultos maiores de 50 anos de idade, o que correspondeu em 1996 a aproximadamente $14 \%$ da população total.

\section{Discussão}

Antes de discutir os resultados propriamente, é importante salientar que o pequeno volume da população Boróro sob análise gerou grandes flutuações nos indicadores demográficos estimados por ano, que se constitui na chamada volatilida- 
População Boróro de Meruri, Garças e Morada dos Boróro, acima de 15 anos, por estado conjugal, segundo o sexo. Mato Grosso, Brasil, 1996

\begin{tabular}{|c|c|c|c|c|c|c|}
\hline \multirow[t]{2}{*}{ Estado conjugal } & \multicolumn{2}{|c|}{ Masculino } & \multicolumn{2}{|c|}{ Feminino } & \multicolumn{2}{|c|}{ Total } \\
\hline & $\mathbf{n}$ & $\%$ & $\mathbf{n}$ & $\%$ & $\mathbf{N}$ & $\%$ \\
\hline Solteiros & 32 & 26,7 & 15 & 13,3 & 47 & 20,2 \\
\hline Casados & 72 & 60,0 & 72 & 63,7 & 144 & 61,8 \\
\hline Viúvos & 2 & 1,7 & 10 & 8,8 & 12 & 5,2 \\
\hline Separados & 14 & 11,7 & 16 & 14,2 & 30 & 12,9 \\
\hline Total & 120 & 100,0 & 113 & 100,0 & 233 & 100,0 \\
\hline
\end{tabular}

Tabela 4

Taxas específicas de mortalidade por idade, por mil habitantes. Aldeias Garças, Meruri e Morada dos Boróro, Mato Grosso, Brasil, 1993-1996.

\begin{tabular}{|c|c|c|c|c|c|}
\hline $\begin{array}{l}\text { Grupo etário } \\
\text { (anos) }\end{array}$ & 1993 & 1994 & 1995 & 1996 & $1993-1996$ \\
\hline $0-4$ & $\begin{array}{c}0,0 \\
(0 / 70)\end{array}$ & $\begin{array}{c}14,1 \\
(1 / 71)\end{array}$ & $\begin{array}{c}14,7 \\
(1 / 68)\end{array}$ & $\begin{array}{c}14,3 \\
(1 / 70)\end{array}$ & $\begin{array}{c}10,8 \\
(3 / 279)\end{array}$ \\
\hline $5 / 14$ & $\begin{array}{c}0,0 \\
(0 / 111)\end{array}$ & $\begin{array}{c}8,0 \\
(1 / 125)\end{array}$ & $\begin{array}{c}0,0 \\
(0 / 117)\end{array}$ & $\begin{array}{c}0,0 \\
(0 / 115)\end{array}$ & $\begin{array}{c}2,1 \\
(1 / 468)\end{array}$ \\
\hline $15-64$ & $\begin{array}{c}10,6 \\
(2 / 189)\end{array}$ & $\begin{array}{c}0,0 \\
(0 / 201)\end{array}$ & $\begin{array}{c}4,9 \\
(1 / 203)\end{array}$ & $\begin{array}{c}4,8 \\
(1 / 208)\end{array}$ & $\begin{array}{c}4,9 \\
(4 / 801)\end{array}$ \\
\hline $65 e+$ & $\begin{array}{c}0,0 \\
(0 / 23)\end{array}$ & $\begin{array}{c}0,0 \\
(0 / 27)\end{array}$ & $\begin{array}{c}80,0 \\
(2 / 25)\end{array}$ & $\begin{array}{c}80,0 \\
(2 / 25)\end{array}$ & $\begin{array}{c}40,0 \\
(4 / 100)\end{array}$ \\
\hline Total & $\begin{array}{c}5,1 \\
(2 / 393)\end{array}$ & $\begin{array}{c}4,7 \\
(2 / 438)\end{array}$ & $\begin{array}{c}9,7 \\
(4 / 413)\end{array}$ & $\begin{array}{c}9,6 \\
(4 / 418)\end{array}$ & $\begin{array}{c}7,3 \\
(12 / 1.648)\end{array}$ \\
\hline
\end{tabular}

de demográfica 18. Este é um fenômeno comum em análises realizadas com dados oriundos de populações de pequena escala, como é o caso de muitos povos indígenas 10 .

O presente estudo mostrou que a população Boróro das comunidades de Meruri, Garças e Morada dos Boróro aumentou de 393 para 418 indivíduos no período de 1993 a 1996, apresentando uma taxa média de crescimento relativamente baixa (2,4\% ao ano). É inferior àquelas encontradas para diversos povos indígenas no Brasil, de cerca de 3,5\% ao ano 11,19. Podem ser citados os exemplos dos Kayabí, habitantes da região central do Parque Indígena do Xingu, que cresceram 5,2\%, entre 1970 e 1999 20; e os Xavánte (Mato Grosso), cujas taxas de crescimento estão próximas de $5 \%$ ao ano $21,22,23$.

Observou-se também que $44 \%$ da população Boróro tinham menos de 15 anos, com ida- de mediana de 16 anos. A parcela de indivíduos com mais de 65 anos, bastante reduzida, era de aproximadamente 6\%. Essa configuração etária jovem é freqüentemente observada em populações indígenas 10.

A mortalidade da população Boróro reflete, principalmente, a precariedade de suas condições de vida. A TMI para o período foi de 58,8 por mil, quase que o dobro daquela do Brasil em 1997 (31,9 por mil). Além das doenças infecciosas e parasitárias, o alcoolismo é um sério problema no caso de jovens e adultos 2,4,24.

Vários autores que escreveram sobre os Boróro enfatizaram as altas taxas de separação de casais e a importância dos vínculos que unem as pessoas pertencentes a um mesmo clã 1,2,4,5,7,25. Novaes 6 escreve que, devido à alta taxa de separação de casais, um homem pode se casar até cinco vezes, de modo que irá morar em várias 
casas ao longo de sua vida. A autora esclarece que, apesar do fluxo constante de pessoas que se agregam e deixam os domicílios, as mulheres constituem minoria nesse fluxo. No caso de separação do casal, as mulheres permanecem na moradia com seus filhos e filhas, fato que se relaciona à regra de residência uxorilocal.

Conforme se observou por meio de análise de nupcialidade, as mulheres se casam mais cedo que os homens. Em 1996, metade das mulheres de 15 a 19 anos já havia se casado, ao passo que $66,7 \%$ dos homens nessa faixa etária ainda permaneciam solteiros. Há também um número expressivo de homens e de mulheres fora de uniões conjugais, sendo a proporção de homens viúvos ou separados de $10,4 \%$, e a de mulheres de $18,8 \%$.

Em estudo sobre as mulheres Kamayurá, Pagliaro \& Junqueira 26 observaram proporções de mulheres solteiras mais elevadas que a encontrada entre as mulheres Boróro. Em 2003, a proporção de mulheres Kamayurá solteiras era de $70,6 \%$ no grupo de 15 a 19 anos de idade, 31,3\% no grupo de 20 a 24 anos e $20 \%$ no grupo de 25 a 29 anos. Por outro lado, a proporção de mulheres Kamayurá maiores de 15 anos de idade que estavam viúvas ou separadas, mas que ainda não haviam contraído nova união foi de 9,6\%. Ou seja, uma porcentagem muito inferior a que se verificou neste estudo (18,8\%).

É possível que a inconstância conjugal entre os Boróro influencie as taxas de fecundidade, que são relativamente baixas (4,3 filhos por mulher, em média) quando comparadas às de outros povos indígenas 18,20,21,27. De fato, as TFTs encontradas para mulheres Boróro que viviam em uniões estáveis e não estáveis foram de 4,7 e 3,4, respectivamente. A TFT no período de 1993 a 1997 para os Xavánte de Sangradouro-Volta Grande, em cuja terra se situa a aldeia Morada dos Boróro, foi de 8,6 filhos 22. Tal padrão de fecundidade, da ordem de 7 a 8 filhos, tem sido observado em diversas outros povos indígenas no país $18,20,21,27$. A partir do presente estudo não é possível apontar as razões para a menor fecundidade das mulheres Boróro, o que merece uma investigação pormenorizada.
Os Boróro afirmam que adotam práticas de restrição voluntária da natalidade, como o uso de ervas de efeito contraceptivo. Em algumas situações, a cultura Boróro legitima o abortamento. Segundo Viertler 7, a decisão de abortar é geralmente advinda de sonhos que trazem maus presságios. Escrevendo na década de 1940, Souza 28 relatou que, por razões econômicas, o aborto pode ser também praticado quando o casal atinge certo número de filhos (próximo de quatro) e quando ainda não foi feita a "esterilização" da mulher através da ingestão de "certas beberagens”. Herbert Baldus 1, que visitou os Boróro de Meruri e Sangradouro (atual Morada dos Boróro) em 1934, atribuiu aos salesianos e à ação missionária as mudanças de comportamento que observou na formação das famílias.

Neste trabalho apresentamos uma análise demográfica da população Boróro de três aldeias realizada com base em dados reunidos ao longo de um período de quatro anos. Um aspecto a ser destacado é que as informações foram coletadas no âmbito das atividades rotineiras de assistência à saúde da FUNAI. Destaca-se a importância da coleta e análise sistemática de dados demográficos para os povos indígenas, úteis no delineamento das condições de saúde e planejamento das ações de educação e saúde, dentre outras áreas 15 .

As análises da nupcialidade, dos níveis de fecundidade e das características das aldeias e famílias, entre outros aspectos, evidenciam a relação entre sistemas sócio-culturais e padrões demográficos no caso dos Boróro, o que se aplica para os povos indígenas de uma maneira geral. É possível que a fecundidade das mulheres Boróro, que é relativamente baixa se comparada a de outros povos indígenas, já tenha esse padrão desde longo tempo. Ou seja, não seria um produto recente derivado somente dos efeitos das atuais condições de vida. Além da expansão dos estudos sobre os povos indígenas de modo a caracterizar a diversidade dos perfis demográficos, é importante levantar dados de modo a evidenciar mudanças ao longo do tempo, em particular buscando relacioná-las com as transformações históricas e sócio-culturais. 


\section{Resumo}

Este estudo descreve o perfil demográfico dos índios Boróro de Mato Grosso, Brasil, no período de 1993 a 1996. O levantamento incluiu cadastros anuais e registros de eventos vitais, coletados a partir das atividades rotineiras do serviço de saúde da Fundação Nacional do Índio, da população de três aldeias (Garças, Meruri e Morada dos Boróro). A taxa média de crescimento foi de $2,4 \%$ ao ano. Observou-se que $44 \%$ da população tinham menos de 15 anos, com idade mediana de 16 anos. Verificaram-se taxas brutas de natalidade de 30,9 por mil e de mortalidade de 7,3 por mil. A taxa de mortalidade infantil para o período foi de 58,8 óbitos por mil nascidos vivos, e de fecundidade total de 4,3 filhos por mulher. As mulheres se casam mais cedo do que os homens e há um número expressivo de adultos, tanto homens $(26,7 \%)$ quanto mulheres $(13,3 \%)$ fora de uniões conjugais. Um aspecto que chama atenção é a relativamente baixa fecundidade encontrada se comparada a de outros grupos indígenas. Destaca-se a importância da coleta e análise sistemáticas de dados demográficos para os povos indígenas.

Demografia; Fertilidade; Mortalidade; Índios SulAmericanos

\section{Referências}

1. Baldus H. Ensaios de etnologia brasileira. São Paulo: Companhia Editora Nacional; 1979.

2. Crocker J. Vital souls: bororo cosmology, natural symbolism and shamanism. Tucson: University of Arizona Press; 1985.

3. Lévi-Strauss C. Tristes trópicos. São Paulo: Editora Martins Fontes; 1979.

4. Novaes SC. Jogo de espelhos: imagens da representação de si através dos outros. São Paulo: Editora da Universidade de São Paulo; 1993.

5. Novaes SC. Mulheres, homens e heróis: dinâmica e permanência através do cotidiano da vida Bororo. São Paulo: Universidade de São Paulo; 1986. (Série Antropologia, 8).

6. Novaes SC. As casas na organização social do espaço Bororo. In: Novaes SC, organizador. Habitações Indígenas. São Paulo: Nobel/Edusp; 1983. p. 57-76.

7. Viertler RB. A noção de pessoa entre os Bororo. Boletim do Museu Nacional 1979; 32:20-9.

8. Ravagnani OM. Os primeiros aldeamentos na província de Goiás: Bororo e Kaiapó na estrada do Anhanguera. Rev Antropol (São Paulo) 1996; 39:222-44.

\section{Colaboradores}

L. G. Souza trabalhou na coleta, organização do banco de dados, análise e redação do artigo. H. Pagliaro e R. V. Santos participaram das etapas de análises e redação do artigo.

\section{Agradecimentos}

Os autores agradecem à Suely Deslandes pelas valiosas sugestões feitas a partir da leitura de uma versão preliminar do trabalho.
9. Ribeiro D. Os índios e a civilização: a integração das populações indígenas no Brasil moderno. 5a Ed. Petrópolis: Editora Vozes; 1986.

10. Pagliaro H, Azevedo MM, Santos RV. Demografia dos povos indígenas no Brasil: um panorama crítico. In: Pagliaro H, Azevedo MM, Santos RV, organizadores. Demografia dos povos indígenas no Brasil. Rio de Janeiro: Editora Fiocruz/Associação Brasileira de Estudos Populacionais; 2005. p. 11-32.

11. Azevedo MM. Povos indígenas na América Latina estão em processo de crescimento. In: Ricardo B, Ricardo F, organizadores. Povos indígenas no Brasil 2001/2005. São Paulo: Instituto Socioambiental; 2006. p. 55-8.

12. Instituto Brasileiro de Geografia e Estatística. Tendências demográficas: uma análise dos indígenas com base nos resultados da amostra dos Censos Demográficos 1991 e 2000. Rio de Janeiro: Instituto Brasileiro de Geografia e Estatística; 2005.

13. Adams K, Price D. The demography of small-scale societies: case studies from Lowland South America. South American Studies 1994; 4:5-10. 
14. Ricardo CA. "Os índios" e a sociodiversidade nativa contemporânea no Brasil. In: Silva AL, Grupione LD, organizadores. A temática indígena na escola. Brasília: Ministério da Educação e Cultura/Organização das Nações Unidas para a Educação, a Ciência e a Cultura/Mari; 1995. p. 29-60.

15. Santos RV, Coimbra Jr. CEA. Cenários e tendências da saúde e da epidemiologia dos povos indígenas no Brasil. In: Coimbra Jr. CEA, Santos RV, Escobar AL, organizadores. Epidemiologia e saúde dos povos indígenas no Brasil. Rio de Janeiro: Editora Fiocruz/ABRASCO; 2003. p. 13-47.

16. Viertler RB. A refeição das almas. São Paulo: Editora Hucitec/Edusp; 1991.

17. Wüst I. Contribuições arqueológicas, etnoarqueológicas e etno-históricas para o estudo dos grupos tribais do Brasil Central: o caso Bororo. Revista do Museu de Arqueologia e Etnologia da Universidade de São Paulo 1992; 2:13-26.

18. Early JD, Peters JF. The population dynamics of the Mucajaí Yanomama. San Diego: Academic Press; 1990.

19. McSweeney K, Arps S. A "demographic turnaround": the rapid growth of indigenous populations in lowland Latin America. Lat Am Res Rev 2005; 40:3-29.

20. Pagliaro H. A revolução demográfica dos povos indígenas: a experiência dos Kaiabi do Parque Indígena do Xingu, Mato Grosso. In: Pagliaro H, Azevedo MM, Santos RV, organizadores. Demografia dos povos indígenas no Brasil. Rio de Janeiro: Editora Fiocruz/Associação Brasileira de Estudos Populacionais/ABEP; 2005. p. 79-102.
21. Flowers NM. Crise e recuperação demográfica: os Xavante de Pimentel Barbosa, Mato Grosso. In: Santos RV, Coimbra Jr. CEA, organizadores. Saúde dos povos indígenas. Rio de Janeiro: Editora Fiocruz; 1994. p. 213-42.

22. Souza LG, Santos RV. Perfil demográfico da população indígena Xavante de Sangradouro-Volta Grande, Mato Grosso (1993-1997), Brasil. Cad Saúde Pública 2001; 17:355-65.

23. Coimbra Jr. CEA, Flowers NM, Salzano FM, Santos RV. The Xavánte in transition: health, ecology, and bioanthropology in Central Brazil. Ann Arbor: University of Michigan Press; 2002.

24. Viertler RB. Alcoolismo entre os Bororo. In: Canesqui AM, organizadora. Ciências e saúde para o ensino médico. São Paulo: Editora Hucitec; 2000. p. 243-61.

25. Crocker J. Reciprocity and Hierarchy among the Eastern Bororo. Man 1969; 4:44-58.

26. Pagliaro H, Junqueira C. Fertility trends and cultural patterns of the Kamaiurá Women, Upper Xingu, Central Brazil. http://www.iussp.org (acessado em Out/2006).

27. Teixeira P, Brasil M. Estudo demográfico dos Sateré-Mawé: um exemplo de censo participativo. In: Pagliaro H, Azevedo MM, Santos RV, organizadores. Demografia dos povos indígenas no Brasil. Rio de Janeiro: Editora Fiocruz/Associação Brasileira de Estudos Populacionais; 2005. p. 135-54.

28. Souza M. A ginecologia e a obstetrícia dos "boróros". Actas Ciba 1941; (12):338-64.

Recebido em 03/Jan/2008

Versão final reapresentada em 27/Jun/2008

Aprovado em 25/Jul/2008 